\title{
The role of organosilicon polymers in the formation of hydrophobic properties of synthetic paint coatings used in building renovation
}

\author{
Wacław Brachaczek
}

\begin{abstract}
The article studies the structure of protective coatings containing organosilicon polymers with different chemical structure, used in the building renovation. The relation between the contact angle of the cured coating and the type of the organosilicon polymer is analyzed. It has been found that the water-repellent properties of the coatings are influenced by the composition of these polymers. Using spectroscopic studies, the mechanism of hydrophobisation of coatings was explained. The analysis of spectral maps along the cross section of the coatings has shown polysiloxane additives migration from the substrate into the coating/air interface. The arrangement of polysiloxanes in cross-section of the coatings was varied and depended on the weight fraction of organic resin in the paint formulation and the chemical composition of polysiloxanes. Tests were carried out using an IR Continuum microscope. The analysis was conducted on cured coatings derived from acrylic paints containing polysiloxanes based on: polydimethyl siloxane PDMS, polymethylvinyl siloxane PMVS and polymethylphenyl siloxane PMPS. The highest mobility was shown by PDMS and PMVS based polysiloxanes. The width of the segregation area for PMPS was greater, which confirms low migration tendency of this polysiloxane.
\end{abstract}

Keywords-Restoration of Monuments, rehabilitation of Buildings, silicone dyeing coats, silicone resin, polymer resin, IR spectroscopy, the surface properties

\section{Introduction}

Proper selection of paint coatings used for renovation of historic buildings ensures the efficiency and durability of conservation treatment. After the restoration of buildings, protective coatings should allow free diffusion of water vapor and protect the walls against the ingress of water from the outside. Water-repellent properties of coatings can be achieved by using different additives. Products containing organosilicon polymers, commonly known as "silicones" or "polysiloxanes," provide extensive possibilities. The essential characteristic of these compounds is assuring hydrophobic properties of the cured coatings while maintaining high water vapor permeability[1,2].

Polysiloxanes are organosilicon compounds, which consist of siloxane chains composed of alternately connected silicon and oxygen atoms. With such a skeleton organic substituents

Wacław Brachaczek (PhD, Eng.) is the academic assistant of the Institute of Civil Engineering at the University of Bielsko-Biała

Poland are linked through $\mathrm{Si}-\mathrm{C}$ bonds, which make these polymers unique in terms of surface properties. They make polysiloxanes widely popular in manufacturing of all kinds of protective coatings. The architectural paints they improve rheological properties, application and their fluidity, anticratering, wettability, etc. In cured coatings they improve flexibility, prevent cracking and improve resistance to weathering [3-5]. This was demonstrated in the latest method of continuous monitoring of strain developed by J. Juraszek. They consist in implementation of FBG (Fiber Bragg Grating) and OTDR (Optical Time Domain Reflectometry) in coatings made of paints containing polysiloxanes [6-11]. They are also added to paint formulations in order to obtain hydrophobic properties of the cured coatings [12]. The compounds most commonly used for waterproofing the paint coatings include silicone polymers with a linear structure, so-called. silicone oils, for example. poly(dimethylsiloxane), PDMS, and branched structure polymers, so-called silicone resins[13].

The behavior of polysiloxanes located at the interface plays a key role in shaping the properties of paints and varnishes. In anticorrosive paints, polysiloxane-based additives to perform their function only when they are transferred to the interface. The ability of the organosilicon compounds to migrate towards the border of the solid and the gas phase (air/coating surface) is a phenomenon known and described in the literature[14-17]. The study of this issue was the subject of the work by Hinder et al. [15]. They demonstrated that the migration of polysiloxanes to air-coating interface in multi-layer anti-corrosion coating systems occurred during coating curing. Horgnies et al. [16,17] proved that migration and segregation of polysiloxane-based additives took place in the coating also after curing. It can be assumed that the phenomenon of the organosilicon compounds migration in the direction of the interface is also present in the polymer paints used to protect the facades. However, in the literature we do not find the answer to how is this phenomenon influenced by polysiloxane structure and the presence of other ingredients of polymer paints. So far no one has analyzed where organosilicon compounds segregation occurs in the cured coatings, what it depends on, and what is the impact of segregation place on the water repellent properties of the coatings. 


\section{Experimental section}

\section{A. Measurement methods}

The samples were studied using a Thermo Continuum IR microscope equipped with a MCT (Mercury Cadmium Telluride) detector cooled with liquid nitrogen. The microscope was coupled to a "Nicolet 6700 " spectrophotometer. A reflexion method was used for the study. The measurement area was $20 \times 160 \mu \mathrm{m}$, where the dimension of $160-\mu \mathrm{m}$ was parallel to the coating cross-sectional surface for better spectral averaging. The measurement step was 10 $\mu \mathrm{m}$ and the number of scans per measurement 1024 . Scanning was performed perpendicularly and at a $45^{\circ}$ to the substrate. The scanning slope was designed to calculate the average of spectra recorded on the coating cross-section length afterwards.

In order to determine the hydrophobicity of the coating, the water contact angle WCA $\theta$, specifying the ability of a paint coating surface to create water-beading effects, was used. It is defined as an angle between the surface of the paint coating and the plane tangent to the surface of the water bordering the paint coating at the contact point of the solid, liquid and gas phases. The angle $\theta$ was measured with a goniometer by observing the contact point of the phases at high magnification.

\section{B. Subject of research}

The subject of research covered architectural paint coatings based on organic resin: styrene-acrylic copolymer, containing the following polysiloxane hydrophobising admixtures with diversified chemical structure:

- SR1: poly(dimethyl)siloxane (PDMS) resin incorporating T, $\mathrm{M}$ and D units, $50 \%$ solid content;

- SR2: poly(dimethyl-co-methylvinyl)siloxane (PMVS) resin, additionally substituted with octyl groups $\mathrm{D}^{\mathrm{Oc}}$ and hydroxyl groups $\mathrm{D}^{\mathrm{OH}}, 50 \%$ solid content,

- SR3: poly(dimethyl-co-methylphenyl)siloxane (PMPS) resin containing, besides methyl groups, approximately $20 \%$ of phenyl groups with DPh units, $50 \%$ solid content.<smiles>CC(C)(C)O[Si](C)(C)C(C)(C)C</smiles>

PDMS

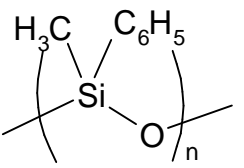

PMPS

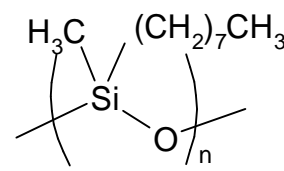

PMVS
Fig. 1. Surface-active polysiloxanes used for hydrophobisation of paint coatings: PDMS - poly(dimethyl)siloxane, PMPS - poly(dimethyl-comethylphenyl)siloxane, PMVS - poly(dimethyl-co-methylvinyl)siloxane.

The other ingredients of the paints included: thickening agent: methyl-hydroxy-ethyl cellulose (MHEC), rheology modifier: xanthan gum, titanium dioxide, rutil, dispersing agent: sodium salt of polyacrylic acid, defoamers, fillers: Plastorit 0 (mica / quarto / chlorite filler), talc, Sachtleben micro (synthetic barium sulfate) and Celatom MW-25 (Diatom).

Figure 2 presents spectra of silicone resins, modified and non-modified, recorded in the medium IR range between $4000-400 \mathrm{~cm}-1$. Structure of all polymers is similar to that of poly(dimethylsiloxanes). There are absorption bands characteristic for silicones visible here, the most important of which are [19]:

- $2967 \mathrm{~cm}^{-1}$ and $2909 \mathrm{~cm}^{-1}$, derived from stretching vibration of the $\mathrm{C}-\mathrm{H}$ bond in $\mathrm{CH}_{3}$ group

- $1414 \mathrm{~cm}^{-1}$, derived from asymmetric deformation vibration of $\mathrm{Si}-\mathrm{CH}_{3}$ group,

- $1267 \mathrm{~cm}^{-1}$, derived from the symmetric deformation vibration of $\mathrm{Si}-\mathrm{CH}_{3}$ group,

- $1111 \mathrm{~cm}^{-1}$ and $1036 \mathrm{~cm}^{-1}$, derived from asymmetric stretching vibration of $\mathrm{Si}-\mathrm{O}-\mathrm{Si}$ group,

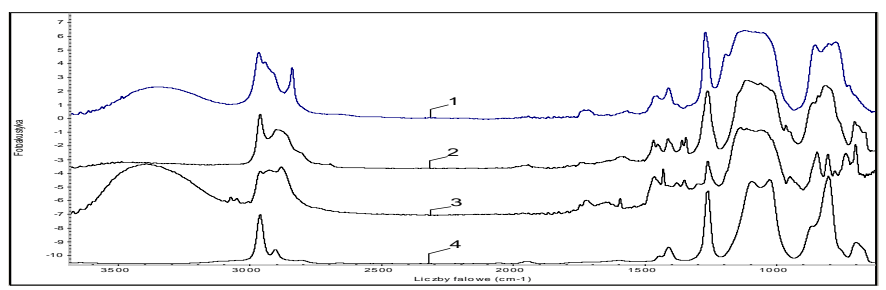

Figure. 2. Summary of photoacoustic FTIR spectra for the analyzed silicone resins: 1 - SR1: PDMS resin, 2 -SR2: PMVS resin with octyl substituents, 3 SR3: PMPS resin, and 4 - the silicone oil spectrum.

Using these components, 30 different variants of paints were prepared. Paint formulations differed in the mass ratio of the $C_{P R}[\%]$ organic resin dispersion to the $C_{S R}[\%]$ polysiloxane dispersion. The $C_{P R}[\%]$ to $C_{S R}$ [\%] ratios in different variants are presented in table 1.

The paint coating were prepared for the tests in the following way: the paint was applied to poly(vinylidene chloride) PVDC foil with a $240 \mu \mathrm{m}$ thick applicator and then, after drying, it was subject to seven cycles of alternate soaking in a water bath with water circulation for $24 \mathrm{~h}$ and drying for 24 h.".

\section{Measurement results}

In order to determine the areas in which polysiloxanes are located in cross-sections of cured coatings, spectral mapping was carried out. Scanning was completed along a line perpendicular to the surface of the test samples. Since the observation of the whole spectrum of the coating was difficult, or even impossible, to interpret, the observation of changes in the chemical composition of the coating was limited to a wave number range of $1100-1250 \mathrm{~cm}^{-1}$, where absorption bands characteristic for silicones, derived from asymmetric stretching vibrations of $\mathrm{Si}-\mathrm{O}-\mathrm{Si}$ groups occur. Figure 3 shows the IR absorption spectrum of the silicone paint coating with a clearly visible band corresponding to the $\mathrm{Si}-\mathrm{O}-\mathrm{Si}$ group.

To determine the size of the area in which the absorption band, characteristic of Si-O-Si groups, was observed in the 
cured coating cross-section, the $S[\mu \mathrm{m}]$ parameter, called "width of polysiloxane placement in the coating," was used.

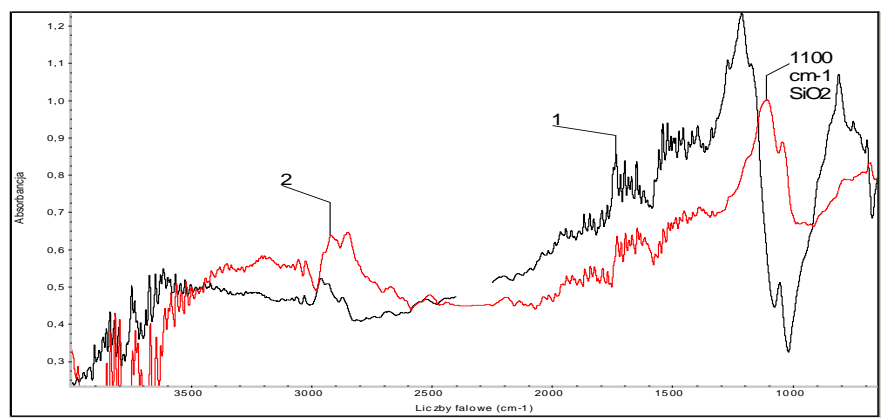

Fig. 3. Spectrum for the paint coating $90 \mu \mathrm{m}$ from the substrate after the Krammers - Kroning correction -1 and the same spectrum, wherein the characteristic silicone band $\mathrm{Si}-\mathrm{O}-\mathrm{Si}$ was observed -2 .

Figure 4 shows the spectral map of the coating containing PDMS (SR1), in which the organic to silicone resin ratio $\mathrm{C}_{\mathrm{PR}}: \mathrm{C}_{\mathrm{SR}}$ was $8: 8$. The analysis of spectral maps in the wave number range of $1100-1250 \mathrm{~cm}^{-1}$ has shown that absorption bands characteristic of $\mathrm{Si}-\mathrm{O}-\mathrm{Si}$ groups are present in the crosssection of the coating at a distance of $70-113 \mu \mathrm{m}$ from the substrate, and throughout the rest of the coating thickness no such bands were found. The $S$ for this coating was $43 \mu \mathrm{m}$.

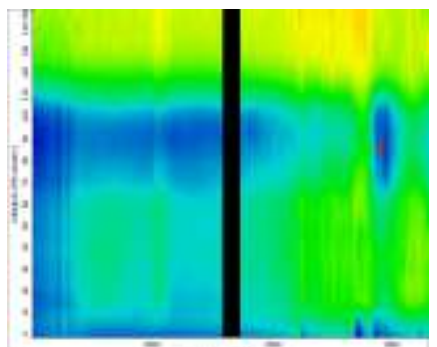

a)

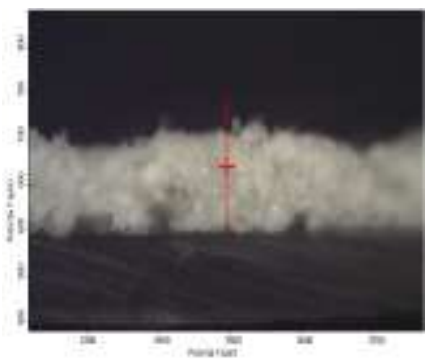

b)

Fig. 4a. A spectral map of the silicone paint coating that includes the PDMS resin SR1 with a $C P R: C S R$ ration at 8:8.

Fig. 4b. A microscopic cross-sectional image of the silicone paint coating with the line of mapping marked.

Similar results were obtained by analyzing the spectral maps of a coating containing PMVS resin. At an identical $\mathrm{C}_{\mathrm{PR}}$ to $\mathrm{C}_{\mathrm{SR}}$ ratio, absorption bands characteristic of $\mathrm{Si}-\mathrm{O}-\mathrm{Si}$ groups are present in the cross-section of the coating at a distance of $71-110 \mu \mathrm{m}$ from the substrate.

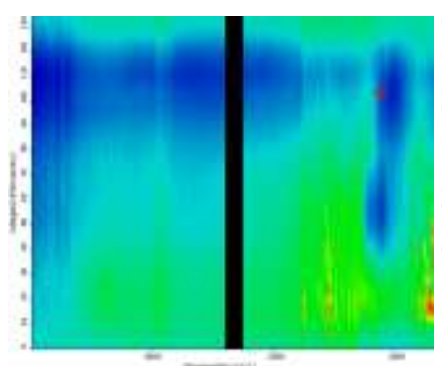

a)

Fig. 5a. A spectral map of the silicone paint coating that included PMPS resin, with $C P R: C S R$ ratio at $8: 8$.
Fig. 5b. A microscopic cross-sectional image of the silicone paint coating with the line of mapping marked.

For coatings containing PMPS (Figure 5), with identical $\mathrm{C}_{\mathrm{PR}}$ to $\mathrm{C}_{\mathrm{SR}}$ ratio, absorption bands characteristic of $\mathrm{Si}-\mathrm{O}-\mathrm{Si}$ groups were present in the cross-section of the coating at a distance of $40-112 \mu \mathrm{m}$ from the substrate. The $S$ for this coating was $72 \mu \mathrm{m}$.

It was also found that the width of the $S$ placement in the hardened paint coating is also affected by the presence of $\mathrm{C}_{\mathrm{PR}}$ organic resin in paint formulation. Figure 6 shows the spectral map of the coating containing PDMS, in which the organic to silicone resin ratio $\mathrm{C}_{\mathrm{PR}}: \mathrm{C}_{\mathrm{SR}}$ was $16: 8$. The width of $S$ for this coating was $76 \mu \mathrm{m}$.
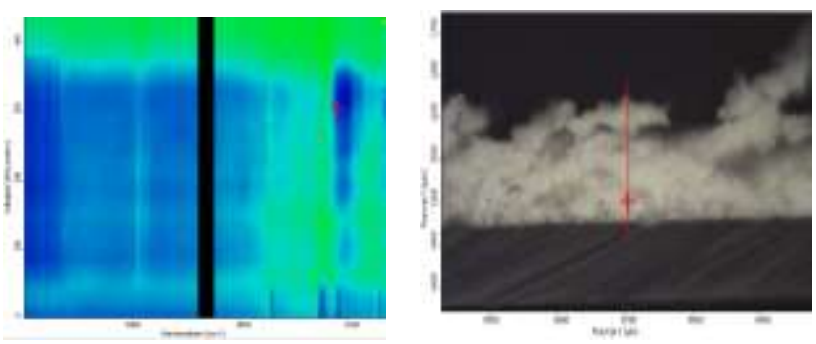

Fig. 6a. A spectral map of the silicone paint coating that includes PDMS resin with a CPR:CSR ration at $8: 8$.

Fig. 6b. A microscopic cross-sectional image of the silicone paint coating with the line of mapping marked.

In order to determine the effect the width of $S$ polysiloxane locating on the hydrophobicity of the cured coatings in each case, contact angle $\theta\left[{ }^{0}\right]$ was measured. It was found that in each of the analyzed cases $\theta$ has different values, which depend on the type of polysiloxanes used in the formulation and the mass fractions of $\mathrm{C}_{\mathrm{PR}}$ and $\mathrm{C}_{\mathrm{SR}}$.

The detailed values of $S[\mu \mathrm{m}]$ and $\theta$ contact angles in the respective coating variants are presented in table 1 .

TABLE I. The width of $S$ polysiloxane locating and $\theta$ contact angle in the tested coatings

\begin{tabular}{|c|c|c|c|c|c|c|c|}
\hline \multicolumn{2}{|c|}{$\begin{array}{c}\text { Mass } \\
\text { fractions }\end{array}$} & \multicolumn{6}{c|}{ Silicone additive } \\
\hline $\begin{array}{c}\mathbf{C}_{\mathbf{P R}} \\
{[\%]}\end{array}$ & $\mathbf{C}_{\mathbf{S R}}[\%]$ & \multicolumn{2}{|c|}{ PDMS } & \multicolumn{2}{c|}{ PMVS } & \multicolumn{2}{c|}{ PMPS } \\
\cline { 3 - 8 } & $\theta\left[^{0}\right]$ & $s[\mu \mathrm{m}]$ & $\theta\left[{ }^{0}\right]$ & $s[\mu \mathrm{m}]$ & $\theta\left[{ }^{0}\right]$ & $s[\mu \mathrm{m}]$ \\
\hline 6.0 & 0.0 & 43.4 & - & 41.3 & - & 44.6 & - \\
\hline 6.0 & 2.0 & 64.8 & 28 & 68.4 & 33 & 52.5 & 49 \\
\hline 6.0 & 4.0 & 92.2 & 31 & 86.4 & 34 & 58.4 & 58 \\
\hline 6.0 & 6.0 & 92.9 & 34 & 102.1 & 37 & 48.8 & 63 \\
\hline 6.0 & 8.0 & 102.9 & 41 & 106.6 & 46 & 59.7 & 64 \\
\hline 8.0 & 0.0 & 61.3 & - & 62.1 & - & 59.8 & - \\
\hline 8.0 & 2.0 & 82.4 & 31 & 78.6 & 36 & 61 & 39 \\
\hline 8.0 & 4.0 & 94.3 & 33 & 98.6 & 43 & 64 & 64 \\
\hline 8.0 & 6.0 & 97.4 & 36 & 107.1 & 42 & 68 & 69 \\
\hline 8.0 & 8.0 & 103.2 & 43 & 106.5 & 39 & 72 & 71 \\
\hline 10.0 & 0.0 & 78.2 & - & 83 & - & 81.5 & - \\
\hline 10.0 & 2.0 & 86.9 & 36 & 88.1 & 44 & 85.1 & 59 \\
\hline 10.0 & 4.0 & 93.7 & 41 & 97.5 & 46 & 87 & 69 \\
\hline 10.0 & 6.0 & 102.6 & 44 & 102.4 & 48 & 86 & 66 \\
\hline 10.0 & 8.0 & 104.4 & 48 & 106.5 & 52 & 89 & 78 \\
\hline 12.0 & 0.0 & 91 & - & 89 & - & 88 & - \\
\hline
\end{tabular}


Proc. of The Third Intl. Conf. On Advances in Civil, Structural and Mechanical Engineering - ACSM 2015 Copyright (C) Institute of Research Engineers and Doctors, USA .All rights reserved.

ISBN: 978-1-63248-083-5 doi: 10.15224/ 978-1-63248-083-5-21

\begin{tabular}{|c|c|c|c|c|c|c|c|}
\hline 12.0 & 2.0 & 98.3 & 49 & 88.4 & 56 & 78.6 & 65 \\
\hline 12.0 & 4.0 & 102.1 & 49 & 96.4 & 54 & 97.4 & 61 \\
\hline 12.0 & 6.0 & 104.6 & 56 & 103.7 & 63 & 83.2 & 78 \\
\hline 12.0 & 8.0 & 104.5 & 54 & 104.9 & 59 & 93 & 82 \\
\hline 14.0 & 0.0 & 97 & - & 98.1 & - & 102.3 & - \\
\hline 14.0 & 2.0 & 93.4 & 59 & 97.3 & 63 & 104 & 72 \\
\hline 14.0 & 4.0 & 102.3 & 64 & 101.3 & 67 & 102.3 & 69 \\
\hline 14.0 & 6.0 & 104.6 & 59 & 103.8 & 59 & 104.6 & 78 \\
\hline 14.0 & 8.0 & 104.1 & 61 & 104.8 & 68 & 104.1 & 88 \\
\hline 16.0 & 0.0 & 92.1 & - & 97.1 & - & 94.1 & - \\
\hline 16.0 & 2.0 & 103.2 & 66 & 102.3 & 69 & 102.6 & 87 \\
\hline 16.0 & 4.0 & 102.1 & 66 & 103.1 & 71 & 103.5 & 79 \\
\hline 16.0 & 6.0 & 103.8 & 71 & 102.3 & 69 & 102 & 79 \\
\hline 16.0 & 8.0 & 102.1 & 76 & 103.1 & 78 & 104.4 & 89 \\
\hline
\end{tabular}

\section{Analysis of results and discussion}

Statistical methods were used for the interpretation of dependencies presented in Table 1. The mathematical relationship between mass fractions of organic resin and silicone resin and the contact angle $\theta\left[{ }^{0}\right]$ and the width of the locating $S[\mu \mathrm{m}]$ was obtained by approximating the dependencies using linear-square polynomials with the general formula:

$\hat{y}=B_{0}+B_{1} \cdot x_{1}+B_{2} \cdot x_{2}+B_{11} \cdot x_{1}^{2}+B_{22} \cdot x_{2}^{2}+b_{12} \cdot x_{1} \cdot x_{2}$

The values of the regression coefficients are presented in Table 2.

TABLE 2 . The results of summary statistics

\begin{tabular}{|l|c|c|c|c|c|c|c|c|c|c|}
\hline \multirow{2}{*}{ Analyzed function } & \multicolumn{8}{|c|}{ Regression function coefficients } & \multicolumn{1}{|l|}{ Regression parame } \\
\cline { 2 - 8 } & $\mathrm{B}_{0}$ & $\mathrm{~B}_{1}$ & $\mathrm{~B}_{2}$ & $\mathrm{~B}_{11}$ & $\mathrm{~B}_{22}$ & $\mathrm{~B}_{12}$ & $\mathrm{R}$ & $\mathrm{R}^{2}$ & $\mathrm{p}$ \\
\hline \multicolumn{8}{|c|}{$\mathrm{SR} 1:$ PDMS resin } \\
\hline$\theta_{1}=\mathrm{f}\left(C_{S R} ; C_{P R}\right)$ & -4.68 & 10.75 & 13.58 & -0.27 & -0.42 & -0.63 & 0.97 & 0.92 & 0.00 \\
$S_{1}=\mathrm{f}\left(C_{S R} ; C_{P R}\right)$ & 15.79 & 0.19 & 1.95 & 0.19 & 0.08 & 0.12 & 0.99 & 0.97 & 0.00 \\
\hline \multicolumn{8}{|c|}{$\mathrm{SR} 2:$ PMVS resin } \\
\hline$\theta_{2}=\mathrm{f}\left(C_{S R} ; C_{P R}\right)$ & -4.68 & 10.75 & 13.58 & -0.27 & -0.42 & -0.63 & 0.97 & 0.93 & 0.00 \\
$S_{2}=f\left(C_{S R} ; C_{P R}\right)$ & 15.99 & 2.01 & 0.76 & 0.09 & 0.1 & -0.07 & 0.97 & 0.94 & 0.00 \\
\hline \multicolumn{8}{|c|}{$\mathrm{SR} 3:$ PMPS resin } \\
\hline$\theta_{3}=\mathrm{f}\left(C_{S R} ; C_{P R}\right)$ & -27.02 & 14.59 & 2.24 & -0.41 & -0.05 & -0.08 & 0.97 & 0.92 & 0.00 \\
$S_{3}=f\left(C_{S R} ; C_{P R}\right)$ & 23.98 & 2.3 & 4.41 & 0.06 & 0.1 & -0.24 & 0.91 & 0.78 & 0.00 \\
\hline
\end{tabular}

Graphic image of the designated statistical functions is presented in graphs 6-10. Figure 7 shows the simultaneous effect of PDMS resin and the organic resin in the paint formulations on the contact angle of the cured coatings. It was found that the greatest impact of the PDMS resin on values $\theta$ occurs at mass fractions of an organic resin $\mathrm{C}_{\mathrm{PR}} \in(6-10) \%$. In the case of coatings for which the percentage concentration by weight of an organic resin was between $C_{P R} \in(10-16)$, the effect of the PDMS resin on the value $\theta$ is negligible.

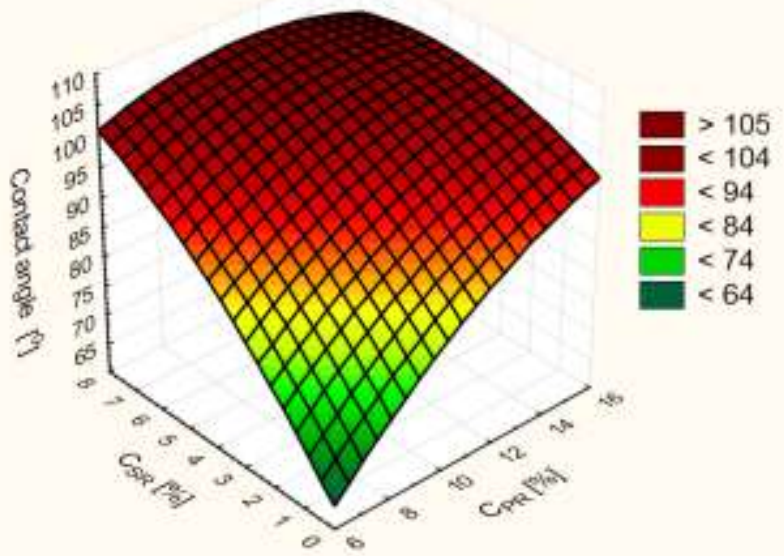

Figure 7. A surface chart of the regression function $\theta_{1}=f\left(C_{S R} ; C_{P R}\right)$

Figure 8 shows the simultaneous effect of the PDMS resin and the organic resin on the segregation width $S[\mu \mathrm{m}]$. A clear impact of changes in the fractions of an organic resin on the segregation width $S$ was found. With mass fractions of organic resin $\mathrm{C}_{\mathrm{PR}} \in(6-10) \%$ the segregation width was the lowest and ranged between 30-40 $\mu \mathrm{m}$. The highest $S$ parameter value of 70-94 $\mu \mathrm{m}$ was determined for $\mathrm{C}_{\mathrm{PR}} \epsilon$ (14-16)\%.

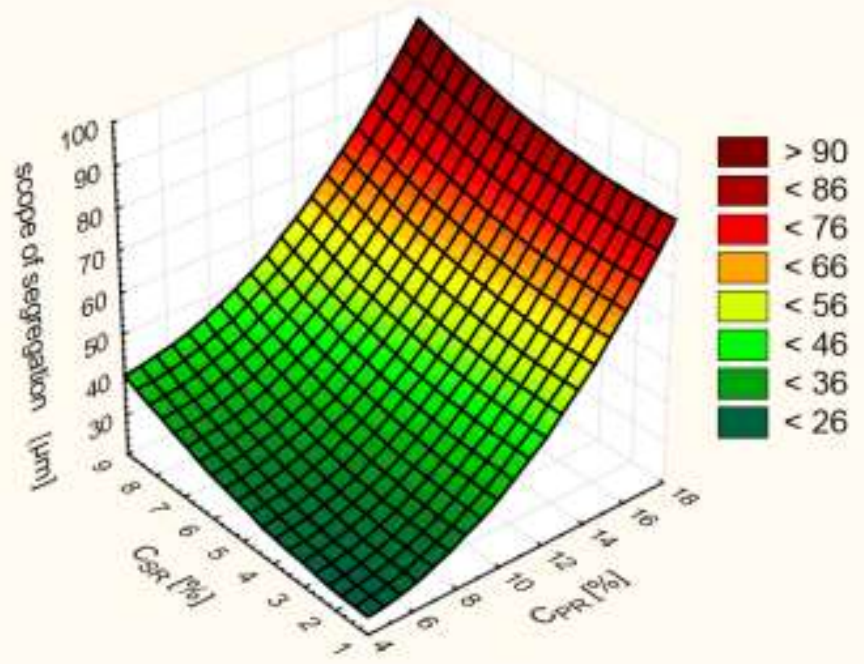

Figure 8. A surface chart of the regression function $S_{1}=f\left(C_{S R} ; C_{P R}\right)$

In order to verify whether the locating width $S$ influences the contact angle $\theta$. the statistical analysis the correlation between these variables was conducted. Visual evaluation of the chart (Figure 9) shows that the relationship is linear. The value of the correlation coefficient was 0.65 , indicating a high linear dependence of the contact angle $\theta$ and the location width $S$. The level of significance $p$ for the $t$ statistic was less than 0.05 , which means that the $\theta$ variability may be described by location width $S$ with high statistical probability. 


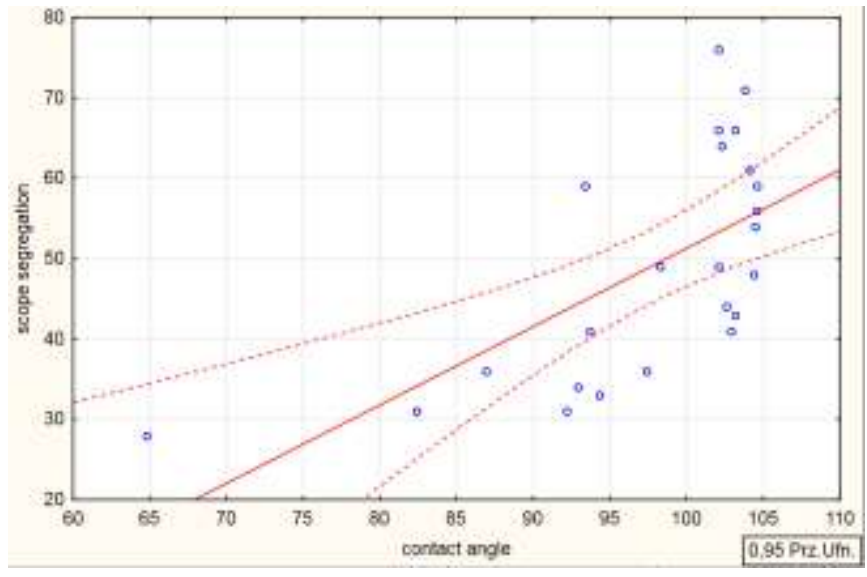

Figure 9. A scatterplot of the location width $S$ against the contact angle $\theta$

A similar analysis was performed for PMVS resin. It was found that also in this case. the greatest impact of the PDMS resin on values $\theta$ occurs at mass fractions of an organic resin $\mathrm{C}_{\mathrm{PR}} \in(6-10) \%$. When examining the correlation between variables $\theta\left[{ }^{0}\right]$ and $S[\mu \mathrm{m}]$, the determination coefficient was 0.66 . which means that $\theta$ variability is explained by the location width $S$ variation in $66 \%$.

Figure 10 shows the simultaneous effect of PMPS resin and the organic resin in the paint formulations on the contact angle of the cured coatings. It was found that the effect of the PMPS resin $\theta$ value is small in the whole range of variation of the mass fractions of organic resin $C_{P R}$.

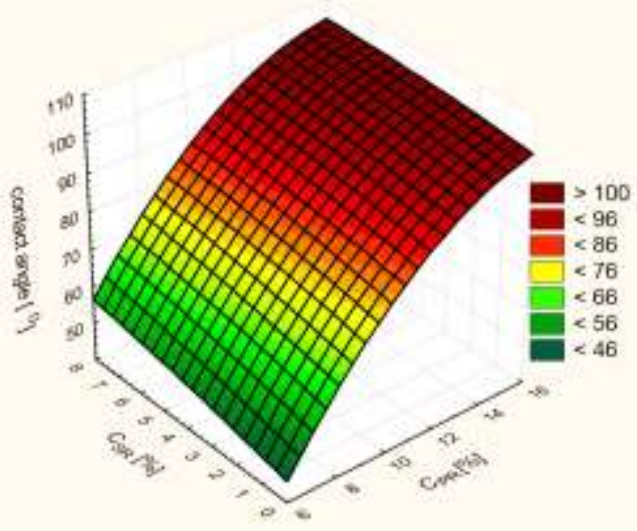

Figure 10. A surface chart of the regression function $\theta_{3}=f\left(C_{S R} ; C_{P R}\right)$

After analyzing all of the regression functions it was found that at fixed $\mathrm{C}_{\mathrm{PR}}$ to $\mathrm{C}_{\mathrm{SR}}$ ratios, the location widths $S[\mu \mathrm{m}]$ vary depending on the chemical composition of polysiloxanes. The smallest area of the coating cross-section was occupied by PMVS and MDMS, and the largest location width was noted for PMPS. It was also found that. irrespective of chemical composition. the location width $S$ of polysiloxanes increased with the increase in the mass fraction of the organic resin in the paint formulation.

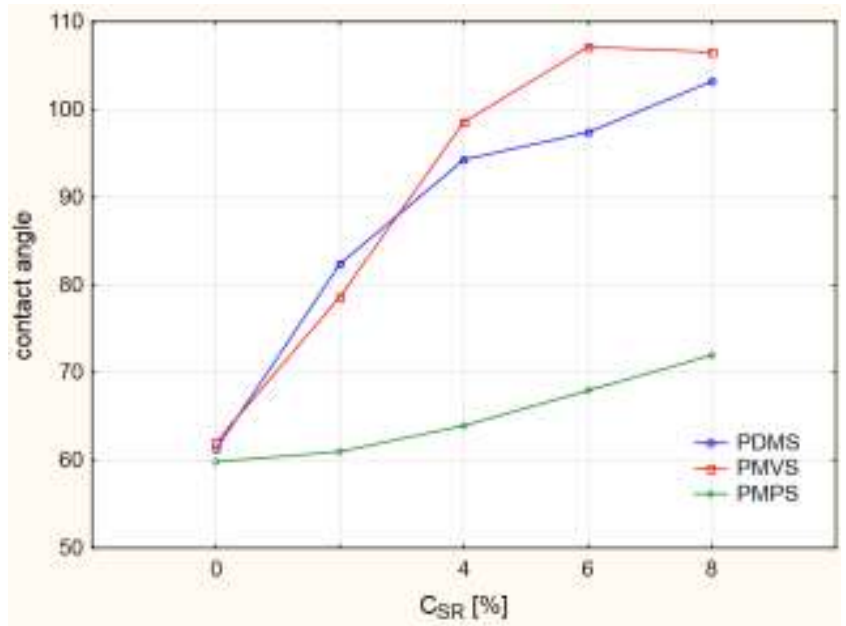

Figure 11. Changes in the contact angle depending on the mass fraction of the polysilixanes resin $\mathrm{C}_{\mathrm{SR}}[\%], \mathrm{C}_{\mathrm{PR}}=8 \%$.

The effect of the analyzed silicone resins on the change of the contact angle $\theta$ for individual polysiloxanes was compared using the same fraction of the organic resin of $\mathrm{C}_{\mathrm{PR}}=8 \%$. Because of the impact of polysiloxane resin on $\theta$, such amount of $\mathrm{C}_{\mathrm{PR}}$ is optimum. Higher fractions of the organic resin affect the $\theta$ value to a small extent. The analysis of measurement results has shown the greatest impact of PDMS and PMVS resins fraction on the $\theta$ parameter. Change in PMPS resin fraction in the paint formulation alters the contact angle to the lowest degree (Figure 11). Figure 12 shows changes in the location width of polysiloxanes depending on the mass fraction of the organic resin $\mathrm{C}_{\mathrm{PR}}[\%]$.

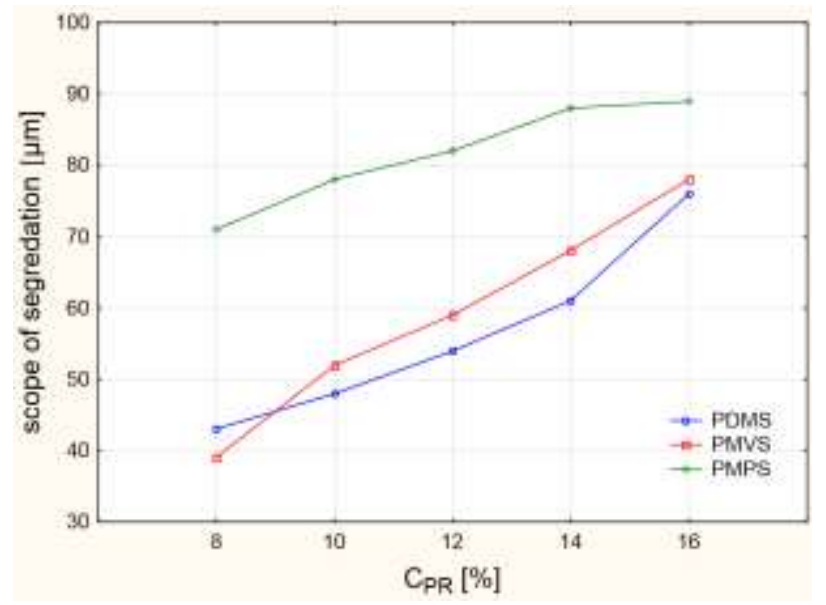

Figure 12. Changes in the location width of polysiloxanes depending on the mass fraction of the organic resin $\mathrm{C}_{\mathrm{PR}}[\%], \mathrm{C}_{\mathrm{SR}}=8 \%$

\section{E. Application significance of the study}

Using modern research methods it has shown that the polysiloxanes are segregated and migrate in the direction from the substrate to the air-coating interface. This phenomenon is 
of key importance to a series of recommendations to be put into practice:

- in the narrowest cross sectional area of the coating. near the air-coating interface. resins containing aliphatic methyl or octyl substituents were segregated. PDMS and PMVS organosilicon polymers form some of the most flexible and mobile polymer chains. wherein the side chains. especially methyl groups. can easily rotate around $\mathrm{Si}-\mathrm{O}$ bond [5. 6]. The change in mass fraction of these resins was the greatest influence on the water-repellent properties of the cured coatings;

- the optimum mass fraction of the polymer resin in the formulation of a paint containing polysiloxanes should not exceed $\mathrm{C}_{\mathrm{PR}}=8 \%$. and silicon resin - not less than $\mathrm{C}_{\mathrm{SR}}=$ $4 \%$;

- the use of a silicone resin with higher fractions of an organic resin is economically unjustified. Too low $C_{P R}$ fractions can cause the polysiloxane to be located too close to the outer surface of the coating. As a result of the natural aging of the coating under the influence of external factors. they may soon be removed from the shell.

\section{Conclusions}

The article analyzes the impact of polysiloxanes of different chemical structure on the changes in the chemical composition of a cross-section of cured coatings. The study was conducted on the example of facade paints containing an organic styrene-acrylic binder. Knowledge of the mechanisms in paint coatings allows to avoid mistakes in developing paint formulations based on polysiloxanes. used in the restoration of monuments. The determined fractions of organic and silicone resin may provide a valuable prerequisite for optimizing production formulas.

\section{References}

[1] W. Heilen, Silicone resins and their combinations, Hannover: Vincentz Network, 2005.

[2] M. Andriot et. al. "Chapter 2 - Silicones in Industrial Applications", Inorganic Polymers, Nova Science Publishers, pp. 61-161, 2007.

[3] W. Heilein, Additives for waterborne Coatings, Vincentz Network, Hannover 2009.

[4] Warrick, E. L., Forty Years of Firsts, The Recollections of a Dow Corning Pioneer, McGraw-Hill, New York, 1990.

[5] N. Auner, G. Fearon, J. Weis, Organosilicon Chemistry III, Part II Silicon based materials introduction, Wiley-VCH Verlag $\mathrm{GmbH}$, Weinheim 1998.

[6] J. Juraszek., Diagnostics of carbon composites using Fibre Bragg Gratings (FBG). CBIDGP, pp. 295-201, 2013.

[7] J. Juraszek, A. Grzywa, Stress and strain analysis with use of the FBG method. CBIDGP,pp..220-230, 2013.

[8] J. Juraszek, Monitoring of structures in civil engineering. Logistics pp. 4956-4965, 2014

[9] J. Juraszek, The clamped joints - a survey and analysis of shapes and materials. Journal of Theoretical and Applied Mechanics, 2006 : Vol. 44, No.1, s.51-73,
[10] J. Juraszek, P. Hatłas, K. Krupa., Implementation of new diagnostic method for energetic connectors. MSM 2009, 22-25 TransTechPub

[11] J. Juraszek., Modelling system for clamped joints, MSM 2009, 22-25 TransTechPub

[12] W. Brachaczek, The modelling technology of protective silicone coatings in terms of selected physical properties: hydrophobicity, scrub resistance and water vapour diffusion. Progress in Organic Coatings 77 (2014) pp. 859-867.

[13] Z. Yang, L. Feng, S. Diao, S. Feng, Ch. Zhang, Study on the synthesis and thermal degradation of silicone resin containing silphenylene units, Thermochimica Acta 521(2011) pp. 170-175.

[14] Dan Mu and Jian-Quan Li, A Study of the Adsorption and Diffusion Behavior of a Single Polydimethylsiloxane Chain on a Silicon Surface by Molecular Dynamics Simulation, Molecular Dynamics -Theoretical Developments and Applications in Nanotechnology and Energy, InTech 2012, pp. 327-338.

[15] S. J. Hinder, Ch. Lowe, J.T. Maxted, J. F. Watts, Migration and segregation phenomena of a silicone additive in a multi-layer organic coating, Prog. Org.Coat 54, pp. 104-112, 2005.

[16] M. Horgnies, E. Darque-Ceretti, R. Combarieu, Influence of additives segregation on surface composition of automotive coatings: effects of an ethanol cleaning, Prog. Org.Coat. 47(2003), p. 154.

[17] M. Horgnies, Evelyne Darque-Ceretti, Study of siloxane additives migration to the surface of polyester-(melamine)-polyurethane coatings: Aging effects after ethanol cleaning, Progress in Organic Coatings 55 (2006), pp. 27-34.

[18] Spectral Database for Organic Compounds SDBS. National Institute of Advanced Industrial Science and Technology. [available 2010-09-02].

About Author (s):

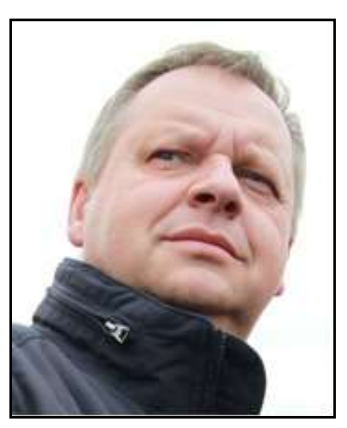

Wacław Brachaczek ( $\mathrm{PhD}$, Eng) is the academic assistant of the Institute of Civil Engineering at the University of Bielsko-Biała. He deals with manufacturing technology and designing mathematical models that identify technological phenomena, setting mathematical models, modeling physical properties of materials classified under the broad concept of construction chemicals. 